Conclusions The findings of this study indicate that VLBW children as a group have more adaptation challenges than their peers born at term. This was still the case when children with CP were excluded.

\section{EVALUATION OF FEEDING-EDUCATION PROGRAMME FOR CHILDREN WITH CEREBRAL PALSY AT INPATIENT PEDIATRIC UNIT: FROM CAREGIVERS' PERCEPTION}

doi:10.1136/archdischild-2012-302724.1242

R Hoque. Dept. of Occupational Therapy, Centre for the Rehabilitation of the Paralyzed, Dhaka, Bangladesh

Objective Evaluate the feeding-education programme of the Paediatric Inpatient Unit of CRP, Savar, Dhaka, from perceptions of caregivers of children with cerebral palsy, who are attending the feeding-education programme.

Methodology The study was conducted using phenomenological method in qualitative approach. Caregivers of children with cerebral palsy were the study participants who stay with their children in the Paediatric Inpatient Unit of CRP and attend the feeding-education programme. Nineteen participants were selected using purposive sample. Data were generated through 7 individual interviews and 3 focus-group discussions and observations within 2 months. Each focus group consisted of 4 participants. Face-to-face interviews were conducted using a semi-structured questionnaire. Data were analyzed using content analysis under category, code and preparing theme for result.

Results The results indicate that the caregivers of children with cerebral palsy felt that the feeding education programme was very important for them and their children. They mentioned that this programme improved the feeding performance of their children and enhanced their learning.

Conclusion The results suggest that the feeding education programme has the potential to make a valuable contribution to education. Caregivers were very satisfied with occupational therapists for their way of teaching, demonstration, and repetition of information for better understanding, which directly help caregivers manage their children's feeding and reduce their stress.

\section{ETIOLOGY AND SEVERITY OF HL, SCHOOL TYPE AND MODE OF COMMUNICATION IN NICU GRADUATES AT 3-5 YEARS OF AGE}

doi:10.1136/archdischild-2012-302724.1243

'EA van de Ven, 'HLM van Straaten, ${ }^{2} \mathrm{AM}$ Oudesluys-Murphy, ${ }^{2} \mathrm{AMH}$ Korver. ${ }^{1} \mathrm{Dept}$ Neonatology, Isala Clinics, Zwolle; 2 Pediatrics, Leiden University Medical Center, Leiden The Netherlands

Background Little is known about follow up of NICU graduates with permanent hearing loss (HL) following introduction of neonatal hearing screening.

Aim Evaluation of etiology, severity of HL, school type and mode of communication in NICU graduates.

Methods All NICU graduates with HL identified at the age of 3-5 years at the speech and hearing centres in the Netherlands were included. Results of 2 stage AABR neonatal hearing screening, medi$\mathrm{cal}$ and audiologic follow up as well as performance measures for school type and primary mode of communication were evaluated.

Results Included were 91 newborns [BW 1990 g (sd 1070); GA 32.9 wks (sd 5.3)]. Of those $5.6 \%$ passed neonatal hearing screening. In $44.3 \%$ moderate HL (40-60 dB), in $23.9 \%$ severe $(60-80 \mathrm{~dB})$ and in $31.8 \%$ profound $\mathrm{HL}(>80 \mathrm{~dB}$ ) was established.

In 33/91 cases parental consent was obtained for adjuvant follow up data. In $30.3 \% \mathrm{HL}$ was of hereditary origin, in $24.2 \% \mathrm{HL}$ was caused by asphyxia, in $9.1 \%$ by CMV-infection. In 8 cases $(24.2 \%)$ no cause was identified.
Up to $71.4 \%$ of NICU graduates attended schools for deaf and hard of hearing, $3.6 \%$ different special education, while $25 \%$ visit regular education. In $82.8 \%$ a combination of spoken en signed language was used for communication.

Conclusions After introduction of AABR universal neonatal hearing screening and early intervention in NICU graduates most affected children have moderate to severe HL, attend schools for deaf and hard of hearing, and use a combination of signed and spoken language at age $3-5$ years.

\section{IMPACT OF ORAL VERSUS INTRAVENOUS IBUPROFEN ON NEURODEVELOPMENTAL OUTCOME: A RANDOMISED CONTROLLED PARALEL STUDY}

doi:10.1136/archdischild-2012-302724.1244

'Z Eras, ${ }^{2} \mathrm{~T}$ Gokmen, ${ }^{3} \mathrm{O}$ Erdeve, ${ }^{1 B}$ Sarıdas, ${ }^{2} \mathrm{E}$ Canpolat, ${ }^{4} \mathrm{U}$ Dilmen. ${ }^{1}$ Developmental Behavioral Pediatrics Unit; ${ }^{2}$ Neonatology, Zekai Tahir Burak Maternity and Teaching Hospital; ${ }^{3}$ Neonatology, Ankara University, Faculty of Medicine; ${ }^{4}$ Neonatology, Zekai Tahir Burak Maternity and Teaching Hospital, YIIdırım Beyazit University Department of Pediatrics, Ankara, Turkey

Objective Although neurodevelopmental outcomes for management of patent ductus arteriosus with intravenous indomethacin and ibuprofen are known, there has been lack of data on long term effects of oral ibuprofen in the literature.

Method To assess the neurodevelopmental outcomes at 18-24 months' corrected age, we conducted a prospective follow-up study of 99 infants with birth weight $\leq 1500 \mathrm{~g}$ and gestational age $\leq 32$ weeks who recieved either oral or intravenous ibuprofen for patent ductus arteriosus.1) Moderate/severe cerebral palsy with functional deficits, 2) bilateral hearing loss and blindness in either eye, and 3) mental developmental index score or psychomotor index score less than 70 were defined as abnormal neurologic, neurosensory and cognitive outcomes, respectively.

Results At 18-24 months' corrected age, neurodevelopmental outcomes of $30(60.0 \%)$ among 50 subjects who received oral ibuprofen were compared with 27 (55.1\%) of 49 who received intravenous ibuprofen by certified and experienced examiners who were blinded to the groups. The results revealed that long term outcomes did not significantly differ among treatment regimes.

Conclusion Preterm infants who were treated with oral ibuprofen for patent ductus arteriosus have similar neurological, neurosensory and cognitive outcomes with patients who recieved intravenous ibuprofen at 18-24 months' corrected age.

\section{LONGITUDINAL FOLLOW UP IN A COHORT OF ELBW/ VLBW INFANTS IN THE CONTEXT OF THE BAYLEY-III STANDARDIZATION IN GREECE}

doi:10.1136/archdischild-2012-302724.1245

'V Soubasi, ${ }^{2} \mathrm{~K}$ Velikos, ${ }^{2} \mathrm{M}$ Michalettou, ${ }^{2} \mathrm{~V}$ Papadopoulou, ${ }^{3} \mathrm{D}$ Zafeiriou, ${ }^{1} \mathrm{P}$ Papakyriakidou 'V Drossou. 11st Neonatal Clinic, Ippokration General Hospital, Aristotle University of Thessaloniki; ${ }^{2}$ Dept of Child Psychiatry, Ippokration General Hospital; ${ }^{3} 1$ st Dept of Paediatrics, Ippokration General Hospital, Aristotle University of Thessaloniki, Thessaloníki, Greece

Background It is not clear whether the Bayley III is overestimat ing cognitive performance or it is a more valid assessment of emerging cognitive skills than the older edition II(Vohr B 2012).

Aim To compare the developmental profile in a cohort of premature infants in two different time points in order to assess the stability of the results, in the context of the Bayley-III standardization in Greece.

Methods Bayley-III scales(cognitive, language, motor, socialemotional, and adaptive behavior), were administered in 103 preterm infants ( $\leq 32$ weeks) at a mean age of $12 \mathrm{mo}$ and $24 \mathrm{mo}$. Infants were divided in 2 groups based to their GA: $A(n=48,24-28 w k s)$, 